\title{
Institutions of Higher Education and the Regional Economy: A Long-Term Spatial Analysis
}

\author{
Hui-chen Wang \\ Department of Economics, University of Mississippi, University, MS 38677-1848, USA \\ Correspondence should be addressed to Hui-chen Wang, hcwang@olemiss.edu \\ Received 28 July 2010; Accepted 10 October 2010 \\ Academic Editor: Björn Lindgren
}

Copyright () 2010 Hui-chen Wang. This is an open access article distributed under the Creative Commons Attribution License, which permits unrestricted use, distribution, and reproduction in any medium, provided the original work is properly cited.

This paper investigates the long-term effects of institutions of higher education (IHEs) on regional economic growth with an application of spatial econometrics. IHEs are classified based on the fields of programs offered and degree-granting activities. I use county-level data for the contiguous US to estimate the marginal effects of IHEs on the changes in log employment and log wages in own counties and neighboring counties between 1970 and 2000. Evidence is found of knowledge spillovers of IHEs, especially for cross-county spillovers. Counties with more IHEs on location or in their neighboring counties experienced modestly faster employment growth over the 30-year period. Institutions offering accredited business programs had much larger effects than the others. With respect to degree-granting activities, only those institutions awarding bachelor's degrees or above had significant growth-boosting effects. When industrial mix of counties is controlled for, own-county effects diminish except for business programs, whereas all neighboring-county effects prevail.

\section{Introduction}

Human capital accumulation and technological change through higher education have been thought to be important determinants of individual earnings and economic growth. In practice, states seeking to improve their economic fortunes frequently turn to local institutions of higher education to participate more fully in economic development; in the meantime, universities tend to promote new economic development agendas as an effort to increase financial support from the state governments (see [1]).

Despite the many potential benefits of higher education at the individual and the economy levels, careful examination on the scope and magnitude of these benefits is necessary to provide justification for the high costs involved in such investments. This may be particularly important for governments that consider spending limited resources to establish or subsidize local universities or colleges. For instance, the values of these institutions to their surrounding communities are limited if they only contribute to the level of economic activity rather than if they also contribute to the economic growth of these areas. These two types of contribution are made possible by two distinct effects of the institutions of higher education, known as the "expenditure effect" and the "knowledge effect".

The expenditure effect refers to the increased demand for consumption generated by faculty, staff, students, and university-related activities. This effect implies that having a new institution of higher education or an increase in size of the institution will increase the level of employment and earnings in the location. While the expenditure effect contributes to the economy of a college location in a direct and immediate way, it only provides a one-shot boost to the economy and therefore is often labeled as a short-term benefit. $^{1}$

On the other hand, it is possible that a region can also receive long-term economic benefits from having a university or college in its location through the knowledge effect, referring to the knowledge production and technology transfer function of universities. Many studies indicate that the nearby presence of research universities fosters the formation and growth of high tech businesses. ${ }^{2}$ This effect can be directly observed in the partnership formed between local industries and an institution's faculty members or research 
facilities. Research Triangle, Route 128 and Silicon Valley are among the prominent examples. Such partnership may originate from knowledgeable faculty members who start up new firms or transfer knowledge and technology to existing firms nearby in exchange for research funding. It is also likely that high-tech firms will be attracted to locate in areas surrounding universities due to the technological advantages and economies of scale. Because faculty-industry partnership is more commonly observed in some fields than the others, the specific programs offered by a university or college are likely to play an important role in the knowledge effect.

Another source of the knowledge effect is the education function of the institutions, namely, the production of human capital. Because universities and colleges are producers of educated workers, an area located around a university or college is likely to have a higher concentration of skilled workers. The higher earnings of college graduates would add to the regional income, and the better-trained workers may have a higher potential to start up or attract new firms. An increase in the supply of highly educated labor may also lead to increased productivity, increased capacity to perform research and development activities, and increased absorption capacity. Recent research suggests that higher concentration of skilled workers may facilitate the invention of new technology and enable the region to grow faster than otherwise (see [2]). The size of educational benefits is likely to vary across institutions, depending on the quality and the types of education offered at the institutions and their graduates' tendency to stay and work in the local area. ${ }^{3}$

Growth theories, the new theories of endogenous growth in particular, suggest that the knowledge effect may help the locations of the institutions of higher education to grow faster in the long run than the areas without the institutions. As houses and producers of knowledge and human capital, these institutions may accelerate the region's capital accumulation and technological change, thereby having a persistent effect on the growth of the economy. ${ }^{4}$

The main interest of this paper to examine the longterm contribution of the institutions of higher education facilitated by the knowledge effect. Therefore, the remaining discussion and analysis will focus on the potential effects of the institutions on measures of economic growth rather than the levels. ${ }^{5}$ The consideration of spatial dependence and the length of analysis period distinguish this paper from related studies. It is critical to examine a long-term phenomenon such as the knowledge effect over a sufficiently long period of time. The author uses county-level data for the United States between 1970 and 2000 and estimate the effects of higher education institutions on the growth of local economic conditions, as measured by employment and wages. This 30 -year analysis period is substantially longer than those in the majority of related studies. In addition, the nature of knowledge spillovers implies that universities or colleges may affect the growth not only in its own location but also in the neighboring areas. Therefore, my analysis takes into account the spatial dependence among counties to capture the potential neighborhood effects. The consideration of spatial dependence proves to be crucial in examining the presence of knowledge spillovers: I find robust evidence of cross-county effects of higher education institutions whereas the evidence of within-country effects is obscure.

The rest of the paper is organized as follows. Section 2 reviews the existing literature, including theories supporting long-term growth effects of institutions of higher education and a review of related empirical studies. Section 3 presents the estimation method, data, and model specification. The estimation results are discussed in Section 4. Section 5 concludes the paper.

\section{Theoretical Framework and Prior Evidence}

2.1. Theories. The role of knowledge spillovers and dynamic externalities has been recognized since Marshall [3] and it has been emphasized in the new theory of endogenous growth since the influential work of Romer [4, 5]. Institutions of higher education participate in the process of technological innovations in a region as producers of basic research and of human capital in the form of higher skilled workers.

In theoretical literature, the most studied mechanism linking higher education institutions to economic growth is perhaps the production externality of human capital. ${ }^{6}$ For example, Lucus [6] argues that the sharing of knowledge and skills though formal and informal interactions generates positive externalities across workers. These externalities are built into the production function by assuming contributions of the average level of human capital to the productivity of all factors of production. Glaeser [7] calibrates this idea in a framework where individuals acquire skills through random contact with more skilled neighbors, and the probability of learning increases with the fraction of skilled individuals in the community and the size of the community. In a model exploring the relationship between the processes of urbanization and growth, Black and Henderson [8] show that individual city sizes grow with local human capital accumulation and knowledge spillovers. They specify localized information spillovers that promote urban agglomeration and human capital accumulation and in turn foster endogenous economic growth of cities. Glendon [2] models the population growth of cities based on the local externalities among skilled workers and derives a pattern of productivity growth similar to the endogenous growth models. Consistent with the suggestions made by Black and Henderson [8], this model predicts that cities with a greater concentration of high-skilled labor will grow faster in terms of population (which also implies faster employment growth). The reason is that process innovations in terms of changes in total factor productivity, made possible only by high-skilled workers, can lead to greater profitability and counteract the congestion costs of a firm operating in a city, thereby enabling the city to grow. ${ }^{7}$

The literature summarized above suggests that higher levels of local human capital will result in faster growth of productivity, employment, and population in a region. If it is believed that the presence of a college or university leads to a greater concentration of skilled labor in the location, the above models provide indirect conceptual support for universities' growth-boosting effects. 
Olsson and Karlsson [9] directly model the relationship between institutions of higher education and the local economic growth. Under the assumptions of diminishing returns and exogenous technological change, the model shows a significant role of universities within a Ramseylike standard solution: even in a world where the steadystate growth rate of consumption and outputs is zero, a region with a university that carries knowledge and produces skills (human capital) relevant to the local manufacturing sector will still grow faster during the transition periods (and has greater steady-state level of outputs) than a region that is not the case. ${ }^{8}$ In addition, this model also suggests that regional growth increases with tightened links between the university and the manufacturing sector. Based on this model, institutions that offer programs in the fields of greater tendency to have industrial or business links would have stronger effects on economic growth.

2.2. Prior Evidence. A large number of empirical studies have linked regional economic development to higher education, many of which focus on the expenditure effects of universities. Some other studies estimate the wage gains from higher education attainment with no account of associated externalities. ${ }^{9}$ However, the most directly related to this paper are the studies examining the economic impacts resulting from knowledge transfer and externalities of universities and colleges, which will be summarized below. ${ }^{10}$

Evidence supporting connection between economic development and the knowledge production of universities has been found using two major approaches. The first approach takes the universities as a primary factor, along with various other factors, to explain the concentration of high technology activities. Spatial dependence is typically specified in this approach to capture the spillover effects from universities. For example, Jaffe $[10,11]$ and Jaffe et al. [12] model spillovers from university R \& D measured by patents, with explicit consideration of the interaction between private firms and university research. One of their findings shows that citations of domestic patents are more likely to be domestic, and they are more likely to come from the same state and SMSA as the cited patents. This localization is found to fade over time, but the fading occurs at a very slow speed. Similarly, Anselin et al. [13] and Varga [14, 15] find evidence of spatial spillovers between university research and high-technology innovative activities.

The second approach focuses on the aggregate economic growth resulting from the knowledge production of universities. These studies generally support that the presence of the university has positive effects on regional growth. For example, Jones and Vedlitz [16] use state-level data in the US for the period between 1979 and 1984 and find a positive relationship between the quality of a state's university system and the growth in aggregate income, income per capita, and net business establishments created. The quality of a state's university system is measured by federal grants received. In addition, state spending on universities is found strongly related to the creation of business establishment and weakly related to university quality.
In a Swedish study, Andersson et al. [17] analyze the relation between regional production and accessibility to infrastructure with an element of the latter being R \& D capacity, measured by the number of full professors in a region. They find that $\mathrm{R} \& \mathrm{D}$ capacity has significant, positive influences on regional productivity, especially when combined with airport capacity. In a case study, Felsenstein [18] estimates both the expenditure and the knowledge-related linkages of a metropolitan university. He finds that the knowledge-related linkages give greater long-term benefits. In an attempt to address the possibility that the rise of the skilled city is the result of a spurious correlation between local skills and omitted urban characteristics, Glaeser and Saiz [19] examine the connection between the number of colleges per capita in 1940 and population growth in metropolitan areas between 1970 and 2000. They find that, as the number of colleges per capita doubles, the population growth rate increases by over 3 percent for both MSAs and cities. ${ }^{11}$ Unlike the first approach, this group of studies does not formally address spatial dependence in the estimation; instead, the spillover effects are simply tested using aggregate place-based data at the state, MSA, or county level.

My empirical analysis integrates the above two approaches in the sense that the author examines the knowledge effect with formal estimation of spatial dependence using spatial econometrics. In addition, this study adds to the literature in several subtler aspects. Firstly, this study estimates spatial dependence at the county level while the related spatial studies of universities generally address spatial dependence at the broader levels, such as cross-state dependence. Secondly, with few exceptions, the previous studies are limited in the length of analysis period, and many of them are cross-section studies. This is highly undesirable for the purpose of examining a long-term phenomenon. ${ }^{12} \mathrm{I}$ investigate economic growth over a 30-year period, which is an improvement over the majority of studies in this genre. It is also worth noting that this study estimates the effect of the production facilities of skills, namely, the institutions of higher education, rather than the effect of the observed skill levels. This approach helps isolate the causal effect of knowledge concentration on regional productivity growth from the possible correlation resulting from skilled workers' preference for local amenity. ${ }^{13}$ Institutions are classified based on the fields of programs offered and their research and degree-granting activities to test the hypotheses of the knowledge effect.

\section{Methodology and Data}

A change-score approach is used to estimate the effects of institutions of higher education (IHEs) on the economic growth of counties in the contiguous US. The independent variables in the regressions are measured at the beginning of the analysis period while the dependent variable is the change in log measures of the economic condition, such as employment or wage rates, between the beginning and the end of the analysis period, 1970-2000. ${ }^{14}$ Therefore, I estimate the marginal effects of having an additional IHE in a county as of 1970 on the rate of employment growth or 
wage growth between 1970 and 2000. ${ }^{15}$ This analysis period is chosen because it is the longest period of time permitted by available data (see details in the data subsection). As mentioned previously, a long analysis period is crucial for the purpose of this study, since the focus is the long-term effects rather than the short-term effects.

The basic regression model is specified in the following equation:

$$
\Delta \ln (Y)=\text { University } \cdot \beta_{1}+X \beta_{2}+u,
$$

where $Y$ represents a measure of economic condition, such as total employment or average wage and salary per job; $\Delta \ln (Y)$ is the change in the natural logarithms of $Y$ in a county from the beginning to the end of the analysis period, which approximates the rate of change in $Y$ during the period; University stands for an $\left(N \times k_{1}\right)$ matrix of higher education institution variables, and $X$ is an $\left(N \times k_{2}\right)$ matrix of other explanatory variables that may influence the economic outcomes, such as the industrial mix of a county. The variables will be discussed in detail later in this section.

The spatial nature of knowledge spillovers presents a unique empirical challenge, namely, the possibility of spatial dependence. ${ }^{16}$ Equation (1) does not take into account spatial dependence across counties and it serves as the preliminary empirical model, from which the complete model of this study will be extended from and compared to. The complete spatial model will be given in Section 3.1. In the second subsection, I will describe the data and measures in this analysis.

3.1. Spatial Dependence Model. To address the dependence of variables across geographic units, a formal econometric method is to apply a spatial version of serial correlation models with a specified pattern of spatial dependency. Spatial dependence may occur in the form of a spatially lagged dependent variable, spatially lagged explanatory variables, or spatial autoregressive errors. A summary of spatial autocorrelation models is provided in the appendix. Because the primary interest of this paper is the spillover effects of universities, I will focus on the model with spatially lagged explanatory variables. Thus, (1) is augmented with spatial lags of the university variables to capture the potential effects of universities/colleges on the nearby areas other than the home county. The resulting spatial model is specified as follows:

$$
\Delta \ln (Y)=\text { University } \cdot \beta_{1}+W \cdot \text { University } \cdot \rho+X \beta_{2}+u,
$$

where $\rho$ is a $\left(k_{1} \times 1\right)$ vector of parameters, and $W$ is the $(N \times N)$ standardized spatial weight matrix, of which the diagonal elements are zeros and the off-diagonal nonzero elements are scaled to sum to unity in each row. More specifically, the element in the $i$ th row, $j$ th column of matrix $W$ can be expressed as

$$
w_{i j}=\frac{c_{i j}}{\sum_{j=1}^{N} c_{i j}}
$$

where $c_{i j}=1$ if unit $i$ is linked to unit $j$, and 0 otherwise. Implied by the row-normalization of the weight matrix, a spatial lag term indicates the average level of the lagged variable in the neighboring units of a geographic observation. ${ }^{17}$ Literally, this weight matrix specifies the membership of neighborhood sets, which may be defined on the basis of shared boundaries or distance bands within which the geographical centroids of neighbors lie.

Because no correlation is specified between the error term and the independent variables, OLS estimators for $\left(1^{\prime}\right)$ retain their desirable properties and are identical to the maximum likelihood (ML) estimators. ${ }^{18}$ Equation ( $\left.1^{\prime}\right)$ is therefore estimated with OLS; meanwhile, ML-based statistical inferences will be reported to facilitate future comparisons among different spatial models.

Computational difficulties arise when estimating a spatial model with a large spatial weight matrix. Every spatial model involves examining the explicit relation between an observation and all other observations. If $n$ observations exist, there will be $n^{2}$ potential relations. Hence, as $n$ becomes large, computing spatial estimators can become very expensive. Pace and Barry [20-22] have conclusively demonstrated that a feasible solution to modeling situations with large $n$ is to exploit the sparse nature of the spatial weight matrix. Spatial autocorrelation usually declines with the increase of distance. Truncating the influence of observations past a certain distance or boundary can greatly reduce the number of relations (nonzero elements) needed to estimate the spatial regression. The sparse-matrix technique stores only the non-zero elements of a matrix and in turn avoids performing unnecessary computation on the zero elements, both saving memory and computing time without the need for supercomputer resources.

Thus, this paper will follow the Pace/Barry technique, written in their Matlab-based Spatial Statistics Toolbox, to construct the spatial weight matrix and estimate the spatial models. In this paper, the author creates the spatial weight matrix based upon Delaunay triangles, which are sets of three lines connecting internal points of three geographical units that are deemed natural neighbors. Only counties included in the same triangle (i.e., counties that are directly connected to one another based on the notion of contiguity) have nonzero entries in the corresponding positions in the spatial weight matrix. Implied by this method is an assumption that two regions are correlated only if they are geometrically adjacent to each other. ${ }^{19}$ Notice that geometrical adjacency determined by Delaunay triagulation approximates geographical adjacency. These two concepts of adjacency do not always agree because that Delaunay triangulation determines adjacency based on the relative positions of the internal points of geographic units, not their physical boundaries. For each county, every neighboring county is assigned the same weight, which is the reciprocal of the total number of the neighboring counties. On average, a county in the continental United States has six neighboring counties.

On account of the nature of spatial dependence, the analyses in this paper include only counties in the 48 contiguous states in the US and the District of Columbia. 


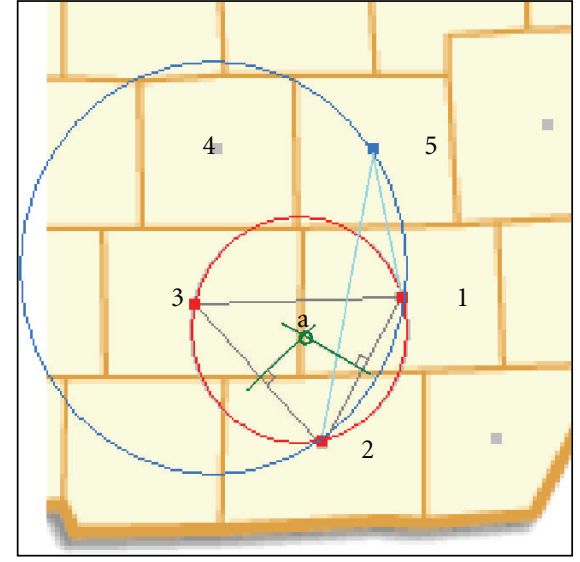

(a)

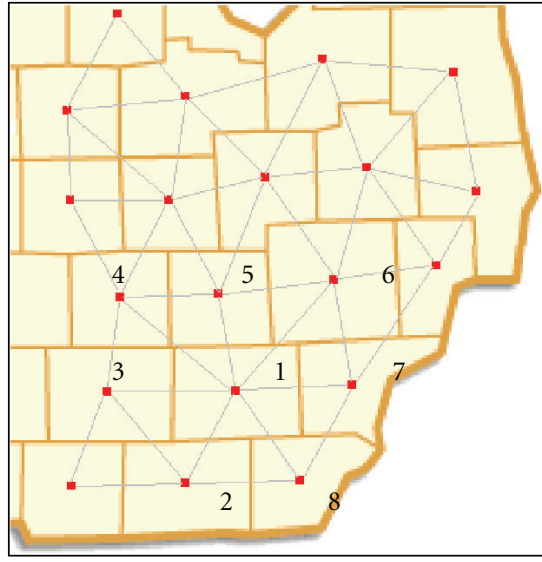

(b)

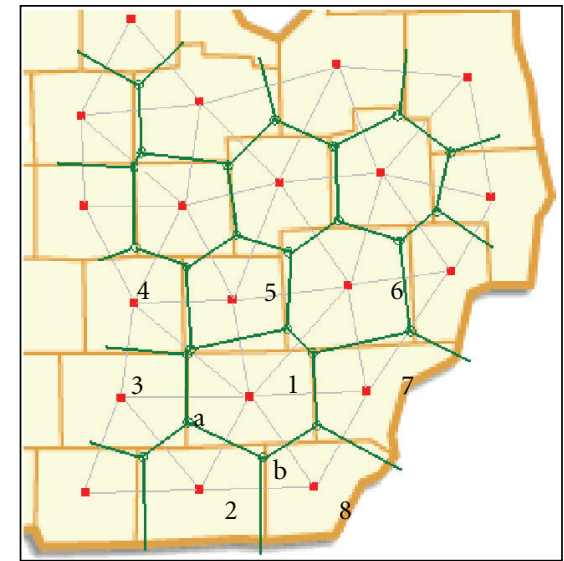

(c)

FIGURE 1: Illustration of delaunay triangulation and voronoi polygons — an example with counties. (a) Identifying a delaunay triangle. The near-rectangular blocks represent selected counties in a certain state, and every county has one unique internal point, indicated by the solid dot in each block. $\Delta 123$ is a Delaunary triangle since no other data point lies within its circumscribed circle. On the other hand, $\Delta 125$ is not a Delaunay triangle because its circumscribed circle contains the internal point of county 4 . This means that at least two of the three counties are not directly connected with one another; in this case, they are county 2 and county 5. (b) Delaunay Triangles. This graph shows the sets of Delaunay triangles covering a larger area of the state. Based on the triangles, seven natural neighbors (counties 2 through 8 ) are identified for county 1. (c) Voronoi Polygons. The Voronoi polygons associated with the Delaunay triangles are formed by the lines connecting the centers of the circumscribed circles. For example, point a is the center of the circle circumscribed about $\Delta 123$ (as shown in part (a)), and point b is the center of the circle circumscribed about $\Delta 128$. Voronoi polygons approximate the geographic boundaries of the counties.

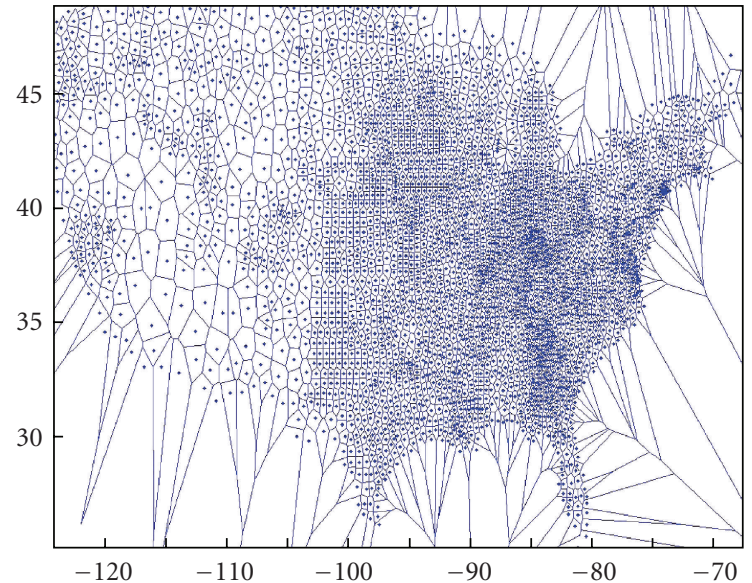

Figure 2: Geometric boundaries between all counties in the contiguous U.S.

\subsection{Data and Measures}

3.2.1. Data. The empirical framework described above requires information on economic growth over a reasonably long period of time and on institutions of higher education at the baseline. This paper uses data from the Regional Economic Information System (REIS) and the Higher Education General Information Survey (HEGIS). Economic growth of a county is measured by the growth of employment and of average wage/salary between 1970 and 2000, data for which are derived from the REIS. The 1970-1971 Institutional Characteristics (ICs) file of the HEGIS provides the baseline information on institutions of higher education.
The REIS, a product of Bureau of Economic Analysis (BEA), provides annual estimates of county employment and wages by place of work beginning in $1969 .{ }^{20}$ The BEA estimates of employment and wages are primarily based on the Census Bureau ES-202 data, which are in turn derived from records of state unemployment insurance (UI) programs and of the unemployment compensation for Federal employees (UCFE) program. BEA then makes adjustments to account for employment and wages not covered or not fully covered by the UI and UCFE programs using additional source data. The ES-202 data accounts for about 95 percent of the wage and salary component of the REIS estimates. The REIS employment estimates measure the number of jobs as opposed to the number of workers. Both full-time and part-time jobs are included in these estimates. Average wage and salary per job are given by the total annual wage and salary disbursements divided by the total wage and salary employment.

The HEGIS was designed by the National Center for Education Statistics to provide comprehensive information on various aspects of all institutions of higher education in the US and its territories. The survey was conducted annually since 1966 until it was replaced by the Integrated Postsecondary Education Data System (IPEDS) in 1986. IHEs are degree-granting postsecondary institutions. These institutions were accredited at the college level by an agency or association recognized by the Secretary, US Department of Education, and they were legally authorized to offer at least a one-year program of study creditable toward a degree. The Institutional Characteristics (IC) component of the HEGIS provides information on basic characteristics of the institutions, including their locations, enrollment, 
and programs offered. Although the HEGIS was first conducted in 1966, the earliest HEGIS-IC file available to the public through International Archive of Education Data (IAED) is for academic year 1970-1971. The 1970-1971 IC file of HEGIS includes a total of 2993 institutions in the US and its territories. After excluding US service schools and institutions located outside the contiguous US, 2929 institutions remain in the sample. In order to categorize institutions based on their research and degree-granting activities, the HEGIS data are merged with the Carnegie Classification of Institutions of Higher Education, 2000 Edition, using Federal Interagency Committee on Education (FICE) codes. ${ }^{21}$ The use of the 2000 version of Carnegie Classification may pose a concern because there may have been changes in the activities and/or the universe of the higher education institutions since 1970. However, for broad classification that distinguishes a research university from an associate's college, it is acceptable to assume that there is no change over time.

For the purpose of estimating spatial dependence models, spatial relationships need to be identified through geographic coordinates of counties. These latitude and longitude coordinates are given by the 1990 Census U.S. Gazetteer files for counties. ${ }^{22}$ In addition to the coordinates data, the Census Gazetteer file also provides other information such as the land area and water area included in a county.

3.2.2. Measures. As mentioned previously, two dependent variables are used in the regressions to capture the economic growth of counties. The first is the changes in log employment between 1970 and 2000, and the second is the changes in log wage rates, measured by average wage and salary per job. $^{23,{ }^{24}}$ The mean change in log county employment over the three decades is 0.51 , indicating a 51 percent growth in employment on average. The mean change in log wage and salary per job is 1.56 , indicating an approximately 156 percent growth in the average wage. Theories suggest that the presence of colleges and universities may lead to persistent economic growth in terms of productivity and, subsequently, employment. At the county level, the closest measure of productivity growth is probably wage growth, which for several reasons is less than perfect. For example, productivity growth accrues only partly to labor; furthermore, in the long run, identical workers must be indifferent across counties as migration occurs. ${ }^{25}$ Therefore, growth in wage rates is likely to be inferior to growth in employment as an indicator of the economic growth of an area. On the other hand, the wage equation may capture some regional influences of the IHEs that are not reflected in the employment equation. A hypothesis is that certain types of IHEs may help to create high-paying jobs in the location. Under this hypothesis, counties with certain types of IHEs may experience overall wage growth differently than other counties, perhaps as a result of a growing concentration of high-paying jobs or as a result of differences in wage growth across professions.

The main independent variable is the baseline number of IHEs located in a county. It is important to note that most colleges that exist in the U.S. today have existed for decades, and most research universities have existed even longer. Therefore, this analysis is examining the effects of a roughly fixed input on the changes in regional economic conditions. ${ }^{26}$ On average, there is 0.95 IHE per county. The number of IHEs in a county ranges from 0 to 66. Among the 3076 counties, 62.5 percent (1892 counties) had no college or university in the location as of 1970, 23 percent (707 counties) had one college or university, 7 percent (215 counties) had two, another 7 percent (214 counties) had three to nine, and the rest 1.6 percent ( 48 counties) had ten or more colleges and universities.

As suggested by the theories, different types of IHEs are likely to differ in their effects on economic growth (Also see [1]). ${ }^{27}$ For example, institutions with greater research capacity are likely to be more influential on economic growth since they carry and produce the more advanced knowledge. Universities with programs such as engineering may also have larger effects due to the stronger tendency of knowledge transfers to local industries. Therefore, it is important to distinguish among different types of institutions based on the programs offered and the emphasis of basic functions, such as teaching and research. For this purpose, the author applys two sets of criteria to select or classify institutions, and separate count variables are calculated for institutions that fit a certain criterion.

The first set of criteria selects institutions based on the fields of programs offered and the size of enrollment. Certain program fields are typically thought to have greater tendencies to establish links with local business or industries, which may in turn lead to greater effects on regional growth. Engineering, business, and medicine are identified as likely fields with such promise. Therefore, the numbers of IHEs that have accredited engineering programs, business programs, or medicine programs are calculated, respectively. Also identified is the number of large IHEs, defined as institutions with enrollment of 10,000 or more as of fall 1970. The expected growth effect of this variable is not as clear. On the one hand, the sizes of institutions are relevant to the regional economy in the sense that large institutions generate greater demand for consumption and more job opportunities than smaller institutions. This size effect is likely to serve as a one-time shock, which boosts the level of the economy but not the growth rate. In fact, institutions of greater sizes may even have an adverse effect on the growth of the local economy due to the lack of commercial activities in a student-filled community. On the other hand, the size of universities is likely to be positively associated with their research capacity, such as the number of faculty members. In this case, larger institutions may indeed have greater contributions to the long-term growth of the economy. Among the 2929 institutions of higher educations in the contiguous US as of 1970, 179 had enrollment of 10,000 students or more as of fall 1970, 267 had at least one engineering program, 144 had a business program, and 95 had at least one medicine program. ${ }^{28}$ Because the above criteria are not mutually exclusive, the coefficient for each of the above count variables indicates the additional effects resulting from the particular types of institutions compared to the other institutions. 
Another set of criteria classifies the institutions of higher education based on their research and degree-granting activities. Institutions are divided into four mutually exclusive categories based on Carnegie Classification: doctoral/master's colleges and universities, baccalaureate colleges, associate's colleges, and institutions not classified as any of the above categories. A doctoral/master's college or university is one that offers doctoral or master's degrees and a wide range of baccalaureate programs. Baccalaureate colleges are undergraduate colleges, which award baccalaureate degrees but not higher degrees. Associate's colleges include community, junior, and technical colleges. These institutions offer associate's degrees and certificate programs but typically award no baccalaureate degree. All remaining institutions of higher education fall into the last category. This group primarily consists of specialized institutions, which typically award a majority of degrees in a single field. ${ }^{29}$ Other institutions included in this group are tribal colleges and universities plus institutions not listed in the 2000 edition of Carnegie Classification. Of the 2929 IHEs, 794 institutions are classified as doctoral/master's colleges/universities, 529 were baccalaureate colleges, 715 were associate's colleges, and 891 were none of the above. On average, a county has 0.26 doctoral/master's colleges/universities, 0.17 baccalaureate colleges, and 0.23 associate's colleges.

Other control variables include baseline measures of log employment, county industrial mix variables, land area, and state dummy variables. For the wage equation, a baseline measure of log average wage and salary is also included.

It is important to control for baseline employment because the growth rate of a county may depend on its initial size and colleges/universities tend to locate in large counties. Given a county's land area, the employment level also reflects the density of working population in a county. ${ }^{30}$ To allow flexibility in the functional form, a quartic of baseline log employment is specified.

County industrial mix is indicated by a set of three variables: employment share of resource sectors, ${ }^{31}$ employment share of manufacturing sector, and a dummy variable indicating that the employment share of either category cannot be identified due to missing values in the employment of a component sector. A total of 395 counties had unidentified industrial mix in 1970. Missing values in sector employment often signal that the county has few establishments in the specific sector. According to the data, the employment share of resource sectors and the number of IHEs are significantly and negatively associated, regardless the institution type (the correlation coefficient between the employment share of resource sectors and the number of all IHEs is -0.33). This suggests that colleges and universities tend to locate in nonresource counties. There is a small, positive association between the employment share of manufacturing sector and the number of IHEs (correlation coefficient is 0.12). With respect to institutions offering programs of specific fields, greater employment share in manufacturing is significantly associated with the presence of engineering programs (correlation coefficient is 0.06 ) but not with business or medicine programs. In terms of institutions' degree-granting activities, greater employment share in manufacturing is more closely associated with the number of baccalaureate colleges than with that of associate's colleges and doctoral/master's institutions (correlation coefficient is $0.16,0.11$, and 0.09 , resp.). The causality of these associations is ambiguous because the presence of colleges and universities may influence the local industrial mix as well as the reverse direction.

Table 1 gives the variable definitions, source of data, and summary statistics. The results of nonspatial and spatial regressions are to be discussed in the next section.

\section{Results}

For the purpose of comparison, models with and without the consideration of spatial dependence are both estimated. Section 4.1 presents and discusses the non-spatial regression results, followed by the results from the complete spatial models in Section 4.2. State dummy variables are included in the control sets of all reported specifications; therefore, these regression results reflect the differences among counties in the same state. ${ }^{32}$

4.1. Nonspatial Regressions. The non-spatial regression results are reported in Tables 2 and 3. Table 2 presents the estimates for the employment equation. The odd- and evennumber columns of the table differ in whether the baseline industrial mix variables are included in the control set. The results show modest effects of IHEs on the growth rate of county employment. Based on the coefficients in column (1), where the county's industrial mix is not controlled for, having one additional college or university in a county in 1970 would lead to an additional employment growth of 1.6 percent in that county over the subsequent 30-year period. This is a very small effect compared to the average growth rate of 51 percent. Column (3) adds the numbers of typespecific institutions. While the number of generic IHEs still shows a significant and positive effect on county employment growth in this specification, institutions offering business programs have a much greater influence than institutions that do not, and the difference made by the presence of business programs is as large as 9.2 percentage points of growth rate. In contrast, engineering programs and medicine programs do not appear to make a significant difference. In addition, the effect of IHEs on the growth rate of county employment does not differ significantly by the institution size. In sum, an additional institution with a business program in 1970 would raise the employment of the host county by 10.6 percent by year 2000 while an institution with no business program would raise the county employment by only 1.4 percent.

Column (5) of Table 2 uses the mutually exclusive Carnegie categories of institutions. The regression estimates indicate significant growth-boosting effects on county employment from colleges and universities that offer bachelor's degrees and above. The marginal effect is 4.7 percent growth in the employment of the host county for the number of doctoral/master's institutions and 3.0 percent growth for the number of baccalaureate colleges. The coefficients of number of associate's colleges and number of all other IHEs are not 
TABLe 1: Variable descriptions, sources of data, and descriptive Statistics.

\begin{tabular}{|c|c|c|c|c|}
\hline Variable Name & Description & Source of data & Mean & Std. Dev. \\
\hline Change in log employment & $\begin{array}{l}\ln (\text { emp. } 2000)-\ln (\mathrm{emp} .1970) \text {, where emp. is the } \\
\text { total number of jobs }\end{array}$ & REIS & 0.51 & 0.45 \\
\hline Change in log wage/salary & $\begin{array}{l}\ln (\text { wage } 2000)-\ln (\text { wage } 1970), \text { where wage is the } \\
\text { average wage and salary per job, in } \$\end{array}$ & REIS & 1.56 & 0.16 \\
\hline Number of colleges & $\begin{array}{l}\text { Number of institutions of higher educations, } \\
\text { academic year 1970-1971 }\end{array}$ & HEGIS 1970-71 IC & 0.95 & 2.83 \\
\hline Number of large colleges & $\begin{array}{l}\text { Number of institutions of higher educations with } \\
\text { enrollment of 10,000 students or more, as of fall } \\
1970\end{array}$ & HEGIS 1970-71 IC & 0.06 & 0.38 \\
\hline Number of colleges_Engineering & $\begin{array}{l}\text { Number of institutions of higher educations with } \\
\text { accredited engineering programs, academic year } \\
\text { 1970-1971 }\end{array}$ & HEGIS 1970-71 IC & 0.09 & 0.39 \\
\hline Number of colleges-Business & $\begin{array}{l}\text { Number of institutions of higher educations with } \\
\text { accredited business programs, academic year } \\
\text { 1970-1971 }\end{array}$ & HEGIS 1970-71 IC & 0.05 & 0.26 \\
\hline Number of colleges-Medicine & $\begin{array}{l}\text { Number of institutions of higher educations with } \\
\text { accredited medicine programs, academic year } \\
\text { 1970-1971 }\end{array}$ & HEGIS 1970-71 IC & 0.03 & 0.24 \\
\hline Number of colleges-Doctoral/Master's & $\begin{array}{l}\text { Number of colleges and universities offering } \\
\text { doctoral or master's degrees, academic year } \\
\text { 1970-1971 }\end{array}$ & $\begin{array}{l}\text { HEGIS 1970-71 IC; } \\
\text { Carnegie } 2000\end{array}$ & 0.26 & 0.86 \\
\hline Number of colleges - Baccalaureate & $\begin{array}{l}\text { Number of colleges offering baccalaureate degrees } \\
\text { but not above, academic year 1970-1971 }\end{array}$ & $\begin{array}{l}\text { HEGIS 1970-71 IC; } \\
\text { Carnegie } 2000\end{array}$ & 0.17 & 0.51 \\
\hline Number of colleges-Associate's & $\begin{array}{l}\text { Number of colleges offering associate's degrees } \\
\text { and certificate programs but not above, academic } \\
\text { year 1970-1971 }\end{array}$ & $\begin{array}{l}\text { HEGIS 1970-71 IC; } \\
\text { Carnegie } 2000\end{array}$ & 0.23 & 0.69 \\
\hline Number of colleges-Other Carnegie & $\begin{array}{l}\text { Number of institutions of higher education in } \\
\text { academic year 1970-1971 not classified as } \\
\text { doctoral/master's/baccalaureate/associate's } \\
\text { institutions in Carnegie Classification } 2000 \text {. }\end{array}$ & $\begin{array}{l}\text { HEGIS 1970-71 IC; } \\
\text { Carnegie } 2000\end{array}$ & 0.29 & 1.40 \\
\hline $\operatorname{Ln}($ emp70) & Natural log of employment 1970 & REIS & 9.05 & 1.34 \\
\hline $\operatorname{Ln}($ wage 70$)$ & Natural log of average wage/salary 1970 & REIS & 8.53 & 0.22 \\
\hline Land area & $\begin{array}{l}\text { Land area included (in thousandths of a square } \\
\text { kilometer) }\end{array}$ & $\begin{array}{l}1990 \text { Census U.S. } \\
\text { Gazetteer files }\end{array}$ & 2483818 & 3375585 \\
\hline Employment share of resource sectors & $\begin{array}{l}\text { Resource sectors' employment divided by total } \\
\text { employment } * 100 \%, 1970\end{array}$ & REIS & 20.14 & 14.30 \\
\hline Employment share of manufacturing & $\begin{array}{l}\text { Manufacturing employment divided by total } \\
\text { employment } * 100 \%, 1970\end{array}$ & REIS & 16.56 & 12.88 \\
\hline Undetermined industrial mix & $\begin{array}{l}\text { Dummy variable indicating missing data on } \\
\text { employment of resource sectors and/or } \\
\text { manufacturing sector, } 1970\end{array}$ & REIS & 0.13 & 0.33 \\
\hline County Latitude/Longitude coordinates & & $\begin{array}{l}1990 \text { Census U.S. } \\
\text { Gazetteer files }\end{array}$ & & \\
\hline
\end{tabular}

REIS: Regional Economic Information System.

HEGIS 1970-71 IC: Higher Education General Information Survey, 1970-1971, Institutional Characteristics.

Carnegie 2000: The Carnegie Classification of Institutions of Higher Education, 2000 Edition. Electronic data file, 4th revision, 2003.

statistically significant. Since the institutions awarding bachelor's or higher degrees distinguish from other types of IHEs typically in the levels of human capital produced and their research capacities, these results provide evidence for the knowledge effect by showing that only the institutions capable of producing sufficiently high level of knowledge and human capital will have persistent effects on growth in the long run.
While the above results show significant growth-boosting effects of colleges and universities, these effects diminish once the baseline industrial mix of the counties is included in the control set. The estimates of specifications including industrial mix variables are presented in columns (2), (4), and (6). The employment share of resource sectors and the employment share of manufacturing sector both predict negative growth in the county employment between year 1970 
TABle 2: Non-Spatial OLS Regressions of Changes in Log County Employment 1970-2000.

\begin{tabular}{|c|c|c|c|c|c|c|}
\hline & $(1)$ & $(2)$ & $(3)$ & $(4)$ & $(5)$ & $(6)$ \\
\hline \multirow{2}{*}{ Number of colleges } & $0.016^{* *}$ & 0.007 & $0.014^{*}$ & 0.006 & & \\
\hline & $(0.007)$ & $(0.006)$ & $(0.007)$ & $(0.006)$ & & \\
\hline \multirow{2}{*}{ Number of large colleges } & & & 0.022 & 0.024 & & \\
\hline & & & $(0.033)$ & $(0.030)$ & & \\
\hline \multirow{2}{*}{ Number of colleges_Engineering } & & & -0.005 & -0.018 & & \\
\hline & & & $(0.033)$ & $(0.030)$ & & \\
\hline \multirow{2}{*}{ Number of colleges_-Business } & & & $0.092^{* *}$ & 0.060 & & \\
\hline & & & $(0.045)$ & $(0.041)$ & & \\
\hline \multirow{2}{*}{ Number of colleges-Medicine } & & & -0.029 & -0.056 & & \\
\hline & & & $(0.052)$ & $(0.048)$ & & \\
\hline \multirow{2}{*}{ Number of colleges-Doctoral/Master's } & & & & & $0.047^{* * *}$ & 0.019 \\
\hline & & & & & $(0.017)$ & $(0.016)$ \\
\hline \multirow{2}{*}{ Number of colleges-Baccalaureate } & & & & & $0.030^{*}$ & 0.021 \\
\hline & & & & & $(0.017)$ & $(0.016)$ \\
\hline \multirow{2}{*}{ Number of colleges-Associate's } & & & & & 0.015 & 0.014 \\
\hline & & & & & $(0.016)$ & $(0.014)$ \\
\hline \multirow{2}{*}{ Number of colleges-Other Carnegie } & & & & & -0.002 & -0.006 \\
\hline & & & & & $(0.010)$ & $(0.010)$ \\
\hline \multirow{2}{*}{ Employment share of resource sectors } & & $-0.018^{* * *}$ & & $-0.018^{* * *}$ & & $-0.018^{* * *}$ \\
\hline & & $(0.001)$ & & $(0.001)$ & & $(0.001)$ \\
\hline \multirow{2}{*}{ Employment share of manufacturing } & & $-0.009 * * *$ & & $-0.008^{* * *}$ & & $-0.008^{* * *}$ \\
\hline & & $(0.001)$ & & $(0.001)$ & & $(0.001)$ \\
\hline \multirow{2}{*}{ Undetermined industrial mix } & & $-0.103^{* * *}$ & & $-0.103^{* * *}$ & & $-0.103^{* * *}$ \\
\hline & & $(0.022)$ & & $(0.022)$ & & $(0.022)$ \\
\hline Observations & 3076 & 3076 & 3076 & 3076 & 3076 & 3076 \\
\hline$R$-squared & 0.226 & 0.351 & 0.228 & 0.352 & 0.228 & 0.351 \\
\hline
\end{tabular}

Standard errors in parentheses.

* significant at $10 \% ; *$ significant at $5 \%$; *** significant at $1 \%$.

Also included in the control set are state dummies, land area and a quartic of log employment (not shown).

and 2000. Their coefficient estimates are robust across specifications, indicating a 1.8 percent decrease in employment when the baseline employment share of resource sectors in the county increases by 1 percentage point, and a decrease of 0.8 to 0.9 percent when the baseline employment share of manufacturing sector increases by 1 percentage point. The negative association between the rate of employment growth and the baseline concentration in resource or manufacturing sectors is not surprising since these two sectors are generally considered declining sectors in the past few decades.

In columns (2), (4), and (6), the coefficients of the college variables remain in the same direction as indicated in their no-industrial-mix counterparts (shown in the left adjacent columns); however, these coefficients are smaller and statistically insignificant in the presence of the industrial mix controls. This change can be explained by the fact that colleges and universities are less likely to locate in counties concentrated in resource sectors. On the other hand, this association does not necessarily imply that the previously shown effects of IHEs on employment growth are not causal. As mentioned in the previous section, while industrial mix can affect the choice of college locations, it is also possible that the presence of a college or university promotes the development in nonresource sectors and helps shape the industrial mix in the area. In the later scenario, the industrial mix serves as a mediator between colleges/universities and the development of regional economy, and these institutions indeed contribute to the long-term growth of the county through shifting the local activities toward fast-growing industries.

Table 3 presents the results of the wage equations. Again, odd- and even-number columns are different with respect to the inclusion of industrial mix variables. Unlike the employment results, the wage results are insensitive to the inclusion of industrial mix variables. In general, institutions of higher education do not seem to promote average wages. Such results may indicate that the institutions do not help create high-paying jobs, or it may be that the creation of highpaying jobs is accompanied by new low-paying jobs (such as secretarial or janitorial jobs). For a majority of the college variables, the coefficients are of a negative sign. Counties with an additional doctoral/master's or associate's college experienced a wage decline of around 10 percent. One exception is the number of institutions offering business programs, which predicts a $3 \%$ increase in average wage and salary in the host county, with or without the industrial mix controlled for. 
TAble 3: Non-Spatial OLS Regressions of Changes in Log County Wage/Salary per Job 1970-2000.

\begin{tabular}{|c|c|c|c|c|c|c|}
\hline & (1) & (2) & (3) & (4) & (5) & (6) \\
\hline \multirow{2}{*}{ Number of colleges } & -0.001 & -0.001 & -0.001 & -0.001 & & \\
\hline & $(0.002)$ & $(0.002)$ & $(0.002)$ & $(0.002)$ & & \\
\hline \multirow{2}{*}{ Number of large colleges } & & & -0.011 & -0.011 & & \\
\hline & & & $(0.009)$ & $(0.009)$ & & \\
\hline \multirow{2}{*}{ Number of colleges_Engineering } & & & -0.015 & -0.015 & & \\
\hline & & & $(0.010)$ & $(0.010)$ & & \\
\hline \multirow{2}{*}{ Number of colleges_-Business } & & & $0.030^{* *}$ & $0.029^{* *}$ & & \\
\hline & & & $(0.013)$ & $(0.013)$ & & \\
\hline \multirow{2}{*}{ Number of colleges-Medicine } & & & -0.006 & -0.006 & & \\
\hline & & & $(0.015)$ & $(0.015)$ & & \\
\hline \multirow{2}{*}{ Number of colleges-Doctoral/Master's } & & & & & $-0.009^{*}$ & $-0.010^{* *}$ \\
\hline & & & & & $(0.005)$ & $(0.005)$ \\
\hline \multirow{2}{*}{ Number of colleges_-Baccalaureate } & & & & & -0.001 & -0.001 \\
\hline & & & & & $(0.005)$ & $(0.005)$ \\
\hline \multirow{2}{*}{ Number of colleges-Associate's } & & & & & $-0.011^{* *}$ & $-0.011^{* *}$ \\
\hline & & & & & $(0.004)$ & $(0.004)$ \\
\hline \multirow{2}{*}{ Number of colleges-Other Carnegie } & & & & & $0.006^{*}$ & $0.006^{*}$ \\
\hline & & & & & $(0.003)$ & $(0.003)$ \\
\hline \multirow{2}{*}{ Employment share of resource sectors } & & -0.0004 & & -0.0003 & & -0.0004 \\
\hline & & $(0.0002)$ & & $(0.0002)$ & & $(0.0002)$ \\
\hline \multirow{2}{*}{ Employment share of manufacturing } & & -0.0001 & & -0.0001 & & -0.00009 \\
\hline & & $(0.0002)$ & & $(0.0002)$ & & $(0.0002)$ \\
\hline \multirow{2}{*}{ Undetermined industrial mix } & & 0.005 & & 0.005 & & 0.005 \\
\hline & & $(0.007)$ & & $(0.007)$ & & $(0.007)$ \\
\hline Observations & 3076 & 3076 & 3076 & 3076 & 3076 & 3076 \\
\hline$R$-squared & 0.460 & 0.460 & 0.461 & 0.462 & 0.462 & 0.463 \\
\hline
\end{tabular}

Standard errors in parentheses.

* significant at $10 \% ; *$ significant at $5 \%$; *** significant at $1 \%$.

Also included in the control set are state dummies, land area, log wage and a quartic of log employment (not shown).

Summarizing the non-spatial results of the employment equations and wage equations, having more institutions of higher education in a county may increase the growth rate of county employment but not the average wage per job. This finding confirms an argument made by Glaeser et al. [23], which states that, for various reasons, wage growth is far less than perfect as a measure of productivity growth and is secondary to employment growth at best. Among other things, it is likely that increases in factor productivities accrue only partly to labor. In addition, migration suggests that identical workers would be indifferent across countries in the long run. More importantly, declining industries might create artificial rises in wages by firing their less able workers first while certain technological innovations can enable firms to hire less expensive workers. This last scenario may help explain the negative coefficients of the college variables in the wage results.

4.2. Spatial Regressions. Tables 4 and 5 report the spatial regression results of the employment equation and wage equation, respectively. Every college variable has a main term, indicating the marginal effect of the number of colleges in the county, and a spatial lag term, indicating the marginal effect of the average number of colleges per neighboring county. ${ }^{33}$ Notice the difference between the interpretations of a main term coefficient and a spatial lag coefficient. The estimated benefit of having one additional college in a county is directly reflected in the main term coefficient; on the other hand, the estimated benefit of having one additional college in a neighboring county is only a fraction of the lag coefficient since the average number of colleges per neighboring county is only raised by the reciprocal of the total number of neighboring counties. For example, for a county that has six neighboring counties, the estimated effect of having an additional college built in its neighboring area is one-sixth of the lag coefficient. In all spatial specifications, the likelihood ratio tests significantly reject the null hypothesis of no spatial dependence at the 1\% level (see LR-lag).

With few exceptions, the coefficients of the main terms of college variables remarkably resemble the corresponding non-spatial regression estimates. This suggests a lack of association between the number of colleges in a county and the number of colleges in the county's neighborhood. If, hypothetically, the number of colleges in a county were significantly correlated with the number of colleges there are in its neighboring counties, the non-spatial coefficient 


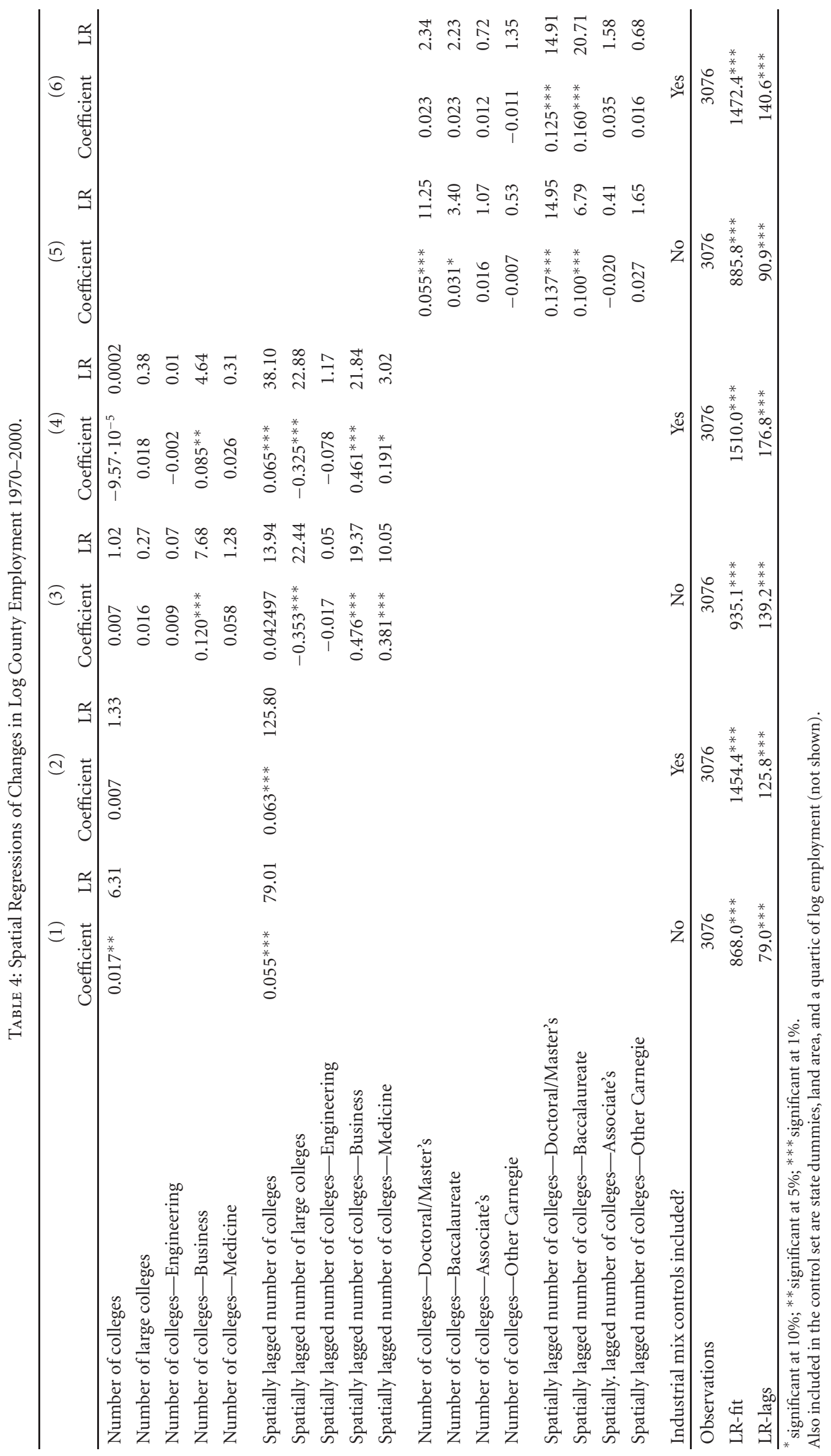




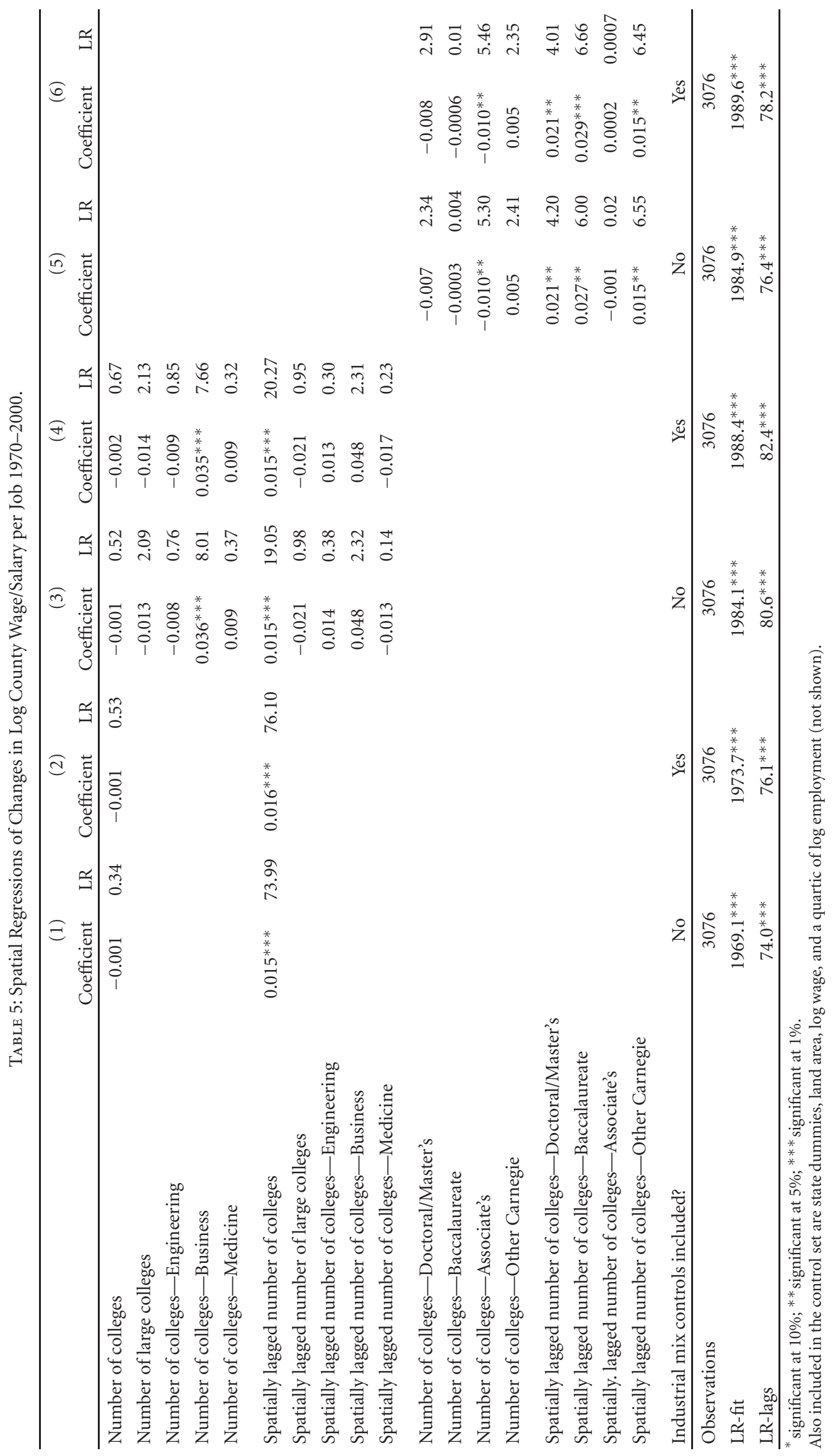


estimates of the main terms would have carried the effects of the omitted spatial lags, if any. This does not appear to be the case here.

In the employment results shown in Table 4, the coefficients of the spatially lagged college variables generally have the same sign as those of their main terms. Coefficients in column (1) imply that having one additional college in a county would lead to a 1.7 percent increase in the county employment over the 30-year period, similar to the nonspatial result. The coefficient of the lagged college variable is 0.055 , indicating that a county would experience an additional 5.5 percent growth in employment if the average number of colleges in the neighboring counties increased by one. For a typical county that has six neighboring counties, this lag coefficient estimate implies that having an additional college in one of its neighboring county would bring a roughly 0.9 percent increase in employment, which is about half the size of the own county effect.

Column (3) of Table 4 adds the numbers of typespecific colleges to the regression. In terms of institution size, counties with large colleges in the neighboring counties experienced falling employment. The marginal effect from having one more large college per neighboring county is as large as a 35.3 percent decrease in employment.

Institutions with business programs, again, led to greater employment growth than the institutions without a business program. According to column (3), a county would experience an additional 12 percent growth in employment if it had one more college on its own land, and an additional 47.6 percent growth in employment if there was one more college per neighboring county, or, equivalently, an additional 8 percent growth for a county with six neighboring counties if there was just one more college in the neighboring area. Engineering programs have not been found to induce employment growth in either the host county or its neighbors. Counties did not experience greater growth by having on its own land an institution offering medicine programs, but they did appear to benefit from having such institutions in its neighboring counties. Having an additional institution offering medicine program per neighboring county would raise the employment by an additional 38.1 percent over the thirty years. Medicine programs were typically built near hospitals, and hospitals are often located in densely populated areas, where the needs for medical treatments are the greatest but the capacity to grow is low. This provides an explanation for the discrepancy between medicine programs' effects on its host county and the neighboring counties. Comparing among the fields of programs, business programs have larger spillover effects than medicine programs and engineering programs. One possible explanation is that business schools often have a large number of part-time students while medical and engineering schools do not. Parttime business school students provide high-quality labor in the surrounding area, and they may start new business themselves.

Coefficients in column (5) indicate that the employment of a county would increase by an additional 3.1 to 5.5 percent if there was a baccalaureate collage or a doctoral/master's institution in the county, and the employment would increase by an additional 10 to 13.7 percent if there was a baccalaureate collage or a doctoral/master's institution per neighboring county. This again provides evidence for the knowledge effects of colleges and universities. Taken together, the above results are consistent with the literature that link research universities to nearby high-tech businesses.

As shown in columns (2), (4), and (6) of Table 4, when the baseline industrial mix variables are included in the control set, the main-term coefficients drop in size and often become insignificant, as in the non-spatial results. In contrast, the coefficients of the lagged college variables are largely unaffected. The robust results of the neighboringcounty effects provide unambiguous evidence for knowledge spillovers from the institutions of higher education.

The spatial results of the wage regressions are presented in Table 5. Similar to the results in Table 3, counties did not acquire faster growth in the average wage by having more colleges in their location (with exception of business programs). However, counties did experience somewhat faster wage growth when there were more colleges in the neighboring counties. The basin-shaped pattern of spillovers is worth noting.

\section{Conclusion}

This paper investigated the long-term effects of universities and colleges on regional growth through knowledge spillovers. As houses and producers of knowledge and human capital, institutions of higher education may accelerate the region's capital accumulation and technological change, thereby having a persistent effect on the growth of the economy. In addition, the nature of knowledge spillovers implies that institutions of higher education may affect not only their own locations but also the neighboring areas. The main goal of this paper is to estimate and distinguish among the effects that different types of institutions have on their location and/or their neighboring areas. I used county-level data from the contiguous United States and estimated the effects of higher education institutions on changes in log employment and log wages for the period of 1970-2000. Spatial dependence among counties was taken into account by applying spatial econometrics.

Non-spatial regression results suggest that the counties with more institutions of higher education in 1970 experienced greater rates of growth in employment over the subsequent 30-year period. Institutions with accredited business programs had much larger effects than the others. In terms of research and degree-granting activities, only the institutions that awarded bachelor's degrees and/or higher degrees had significant effects on the growth rate of county employment. On the other hand, the coefficients of the college variables become insignificant and smaller in size once the baseline measures of local industrial mix are included in the control set. This is explained by the negative association between the employment share of resource sectors and the number of colleges in a county. Because the causality of this association is ambiguous, there remains a possibility that colleges and 
universities had promoted the regional growth through the mediation of local industrial mix.

The spatial regression results are largely consistent with the non-spatial results where the models overlap. With few exceptions, the coefficients of the main terms of college variables resemble the corresponding non-spatial regression estimates. On the other hand, the consideration of spatial dependence in these models provides new and robust evidence for knowledge spillovers. According to the coefficients in the employment regressions, institutions of higher education generally affect the employment growth of the host county and its neighboring counties in the same direction. Comparing among fields of programs offered at an institution, business programs have larger spillover effects than medicine programs and engineering programs. In terms of research and degree-granting activities, institutions that awarded bachelor's degrees and/or above had significant effects on the growth rate of employment in both the host county and its neighboring counties. In addition, doctoral/master's colleges and universities have greater effects on county growth rate than do baccalaureate colleges. Most importantly, unlike the own-county effects, the neighboringcounty effects remain strong even when counties' industrial mix is controlled for. These results substantiate the importance of addressing spatial dependence, and they provide strong evidence for the knowledge effects by showing the significance of the research and education functions of the higher education institutions.

\section{Appendix}

\section{A Summary of Spatial Autocorrelation Models}

While spatial autocorrelation models are similar to timeserial analysis in concept, the spatial version is more complicated and sometime poses a more severe problem than its temporal counterpart. Among other things, the cross-unit relationship in a spatial analysis is multidimensional and the dependence between two geographic units can be two-sided whereas in a time-serial analysis an observation of a certain period can only be influenced by factors in the previous periods but not the reverse.

Consider the following general linear regression model for spatial cross-sections $(n=1,2, \ldots, N)$ :

$$
\begin{array}{r}
y=\zeta W y+X \beta+W X^{*} \rho+\varepsilon \\
\text { with } \varepsilon=\lambda W \varepsilon+\mu,
\end{array}
$$

where $y$ is an $(N \times 1)$ vector of observations on a stochastic dependent variable taken at each of $N$ locations, $X$ is an $(N \times k)$ matrix of nonstochastic explanatory variables, and $X^{*}$ is the $(N \times(k-1))$ matrix of the explanatory variables excluding the constant term. $\zeta$ and $\lambda$ are scalar parameters, $\rho$ is a $((k-1) \times 1)$ vector of parameters, $\beta$ is an $(k \times 1)$ vector of parameters, $\mu$ is an $(N \times 1)$ vector of white noise error terms, and $\varepsilon$ is a vector of spatial autoregressive errors. $W$ is the $(N \times N)$ spatial weight matrix as specified in Section 3.1.
Various combinations can be derived from the model given by (A.1) ${ }^{34}$ Using a non-spatial linear model with spatial data is equivalent to assuming that $\zeta=\lambda=0$ and $\rho=(0, \ldots, 0)^{\prime}$.

Distinguishing among different types of spatial dependence is critical from an econometric point of view. Unlike its time-series counterpart, ordinary least squares (OLS) estimators of a model with a spatially lagged dependent variable are biased and inconsistent due to the two-sided nature of spatial dependence. In contrast, in the case of spatially lagged exogenous variables, OLS estimators of the spatial model retain their desirable properties and are identical to the maximum likelihood (ML) estimators.

\section{Acknowledgments}

The author is grateful to Dan Silverman, John Bound, Julie Berry Cullen, Sheldon Danziger, John Conlon, participants of the economics seminar at the University of Mississippi, Marianne Bertrand, Katharine Abraham, and the anonymous reviewers for their helpful comments on earlier drafts of this paper. She also would like to thank Gordon Hanson and Michelle White for their valuable advice at the exploratory stage of this study. All remaining errors are hers.

\section{Endnotes}

1. Though labeled as "short-term", the expenditure effects often take place in the form of a recurring income stream. The consumption of faculty, staff, and students is obviously recurring. Another example is that a university may attract visitors year after year through activities such as sport events. Still, such benefits only contribute to the level of the local economic activities and will not promote growth if the size of the recurring benefits stays constant over time.

2. For example, Glasmeier [24] relates the presence of universities to the locations of high-tech plants in the U.S. metro areas. Zucker et al. [25] find evidence in the U.S. biotechnology firms that the timing and location of new firms are explained by the presence of scientists. Harhoff [26] finds in West Germany that the presence of scientists or engineers is positively linked to the formation of high-tech firms but not other industry. Kirchhoff et al. [27] link university R \& D expenditures to new firm formation and thus to the growth of employment.

3. The benefits will spill over or "leak" out of the location because the students do not necessarily stay in the area after graduation. State universities and community colleges offer lower tuition for residents, which may lead to a higher resident-nonresident student ratio. If resident students are more likely to stay in the area after graduation than nonresidents, state universities and community colleges would be more beneficial to their local economy than private schools, holding school size and quality constant. 
4. With assumptions of exogenous technological change, constant returns to scale, and diminishing returns of capital, the Solow growth model suggests that the growth rate of an economy will slow down as it develops and eventually converge to a constant steady-state level, and the steady-state growth rate of per-capita output or consumption is solely determined by the exogenous rate of technology growth. Based on this model, the presence of a university may increase the level of local economic wellbeing as it is a permanent shock to the economy, but it will not affect the regional growth rate in the long run, unless it results in a faster technological change in the located region relative to others (which violates the assumption of exogenous technology change). If one can further assume that technology is perfectly mobile in the long run, then the regional advantage in terms of a higher growth rate due to universities, if any, will eventually come to an end. Considering the endogeneity and externalities of technology change and human capital accumulation, recent development of endogenous growth models provides a better reason to maintain an interest in the regional effects of universities.

5. This paper does not claim to empirically examine the hypothesis that the presence of colleges or universities will have permanent, nonconvergent effects on regional growth since this examination would require an extremely long horizon of data, which is not possible despite the author's best effort. Instead, the reported results are better interpreted as evidence for the period of analysis.

6. See [28] for a more general survey of the theoretical literature on human capital externalities.

7. A key assumption of this model is that the ratio of highto low-skill workers determines the share of each skilled worker's time spent on innovative activities. Each skilled worker's innovations then add to the city's total factor productivity and result in significant local externalities. The growth rates of productivity and population thus rise with an increase in the ratio of high- to low-skilled workers.

8. Olsson and Karlsson's growth model features a university sector and a manufacturing sector. A university may be engaged in two activities: education, which produces increases in the stock of human capital, and research, which produces increases in the stock of scientific knowledge. Both human capital and scientific knowledge are inputs used in the production of the manufacturing sector. The assumption of exogenous technological change restricts the model to a world in which there is a lack of research activity so that a university region has no influence on the stock of knowledge. Nonetheless, the manufacturing sector still benefits from knowledge spillovers from a university because the full stock of scientific knowledge is specified to be carried and fully accessible only on a university location and therefore a local public good in this model.
While this study also includes a discussion of the optimal allocation of inputs between education and research, it did not extend to analyze the potential effect of university research on regional growth. Implicitly in the model, although research activities make it possible for a university location to influence the stock of scientific knowledge, a newly invented knowledge will instantaneously transfer from its origin to all universities by the assumption that any university carries the whole stock of existing knowledge. Therefore, research activities in a local university do not imply a technological advantage over other university locations. In reality, however, the transfer of knowledge from one university to another may not be instantaneous and cost-free; thus a university location where research and inventions take place may benefit more or faster from the inventions, leading to a faster growth.

9. Leslie and Slaughter [29] categorize these studies into three groups: rate of return studies, which analyze the returns to human capital investment (e.g., [30-34]), gross accounting studies, which measure the economic gains by aggregating national income growth and partitioning out sources of the growth among the three classic factors, where education is regarded as "improvement in labor" (e.g., [35-38]), and economic impact studies (EISs), which measure the current year collegerelated spending in the local area and are generally used by universities and colleges to measure their economic contribution to the local community. EISs use simple models designed to reflect the immediate and direct benefits rather than to give a comprehensive, in-depth picture of all possible economic relationships between a college and a community (see [39]).

10. More related studies can be found in literature on firm location (e.g., $[20,25,40])$, innovations, and externalities (e.g., [23, 41-44]).)

11. Some other evidence of human capital spillovers may serve as indirect supports for the long-term growth effects of universities. For example, Rauch [45] argues that the average level of human capital is a local public good, and cities with higher average level of human capital should therefore have higher wages and higher land rents. This prediction was supported by data for Standard Metropolitan Statistical Areas (SMSAs) in the United States, where the SMSA average level of formal education and work experience are used as proxies for the average level of human capital. Peri [46] estimates the human capital externalities in U.S. cities by expressing estimated productivity of different labor skills in city-industries as a function of local supplies of skills in the city-industries and in the cities. Glendon [2] shows that the concentration of skilled workers induces population growth of the metropolitan areas. Moretti [47] examines plant-level production in the U.S. cities. He finds that the output of plants located in cities with large increases in the share of college graduate rises more, and the estimated productivity differences between cities with high and low human 
capital match well with differences in labor costs. Several recent studies, such as Shapiro [48] and Glaeser and Saiz [19], attempt to separate the impact of human capital on city growth into a component that is due to enhanced productivity growth and a component that is due to improvements in amenities. Both studies find evidence suggesting that the connection between human capital and city growth occurs largely because skilled cities are becoming more economically productive rather than because they are becoming more attractive place to live. Cheshire and Magrini [49] measure local human capital with the ratio of university students to population and find it to be an important factor in explaining the differential growth rates in real GDP per capita across EU urban areas.

12. This is especially the case because higher education stimulates economic growth with a considerable lag. For example, Parsons [50] proposes that the relocation of high-technology industry is encouraged by an innovation process that takes seven to ten years to complete. Furthermore, theories suggest that locations with more universities could show greater growth indefinitely during the transitional periods, if not permanently.

13. This distinguishes this analysis from the class of studies estimating skill concentration in a location on its economic growth. As discussed by Shapiro [48] and Glaeser and Saiz [19], a positive relationship between the concentration of skilled workers and the regional growth may be explained by mechanisms other than the productivity growth because, for example, high human capital individuals are more likely to reside in locations with higher quality of living and to encourage the growth of the local amenity. Therefore, using the production facilities of skills as the explanatory variable has an advantage over direct measures of skill levels in the sense that the former is less likely to reflect reverse causality or omitted factors.

14. This approach also reduces the potential issue of endogenous education inputs, provided that the initial numbers of universities are orthogonal to the endogenous changes in the numbers caused by concurrent economic outcomes.

15. I have also experimented with shorter periods of analysis, namely the period between 1970 and 1980 and the period between 1970 and 1990. The results are qualitatively consistent across periods of choice. In the employment regression results, where positive growth effects of colleges are found as reported later, the sizes of coefficients are generally smaller for the shorter periods. In the wage regression results, where the estimated own county effects of colleges are mostly negative or insignificant, the negative effects are somewhat larger in the first decade.

16. The same spatial nature also suggests the importance of choosing the appropriate geographic unit of analysis. Units that are too small or too large would both be problematic. While a university or college may induce additional economic activities in nearby areas, the immediate surroundings of the institution may be filled with student-related activities and harbor relatively few commercial or manufacturing activities. Therefore, an overly small unit may not be adequate to capture the growth boosting effect of an institution. In contrast, a unit that is too large would fail to take into account the heterogeneity within the unit and provide fewer observations. In this paper, I choose counties as the unit of analysis as a midway between cities and states.

17. Alternatively, one may choose to use a nonstandardized spatial weight matrix, which gives every neighboring unit a weight of one. Under this specification, a spatial lag term indicates the aggregate level of the lagged variable in all neighboring units. The underlying spatial relationships are different between the two alternative specifications; one assumes that the marginal effect of the average measure is constant, while the other assumes that the marginal effect of the aggregate measure is constant. On the other hand, in the special case where every spatial unit has the same number of neighbors, these two specifications would indicate the same spatial relationship, and the only difference would be the scale. The author also experimented with a non-standardized spatial weight matrix and obtained results similar to those reported (see Section 4 and Endnote 33 for details).

18. This statement is not to be taken as a justification for the OLS estimates of the nonspatial specification. When an important spatial lag is omitted in a model, the OLS estimates will suffer from the standard omitted variable bias since a spatial lag is typically correlated with its main term.

19. Delaunay triangulation returns a set of triangles such that no data points are contained in any triangle's circumscribed circle. Related with a Delaunay triangulation is a Voronoi diagram-the circle circumscribed about a Delaunay triangle has its center at the vertex of a Voronoi polygon. See Matlab Function Reference on Delaunay, Documentation for Mathworks Products (Release 13). Based on this technique, the spatial dependence between observations is measured by their geometric boundary (given by the Voronoi Polygons) rather than the geographic distance between counties, and two regions are considered natural neighbors if they are geometrically adjacent to each other. See Figure 1 for graphic illustrations for Delaunay triangles and Voronoi polygons using an arbitrarily chosen set of counties somewhere in the contiguous US. See Figure 2 for the resulting geometric boundaries of all counties in the contiguous US.

20. Some counties are combined into single observations in REIS. Any set of counties that were combined in REIS for either 1970 or 2000 are treated as one observation for this analysis, leaving 3076 observations on counties or combined units in the contiguous United States. 
The same aggregation is performed for data from all other sources.

21. Carnegie Foundation for the Advancement of Teaching, the Carnegie Classification of Institutions of Higher Education, 2000 Edition, electronic data file, fourth revision 2003.

22. These coordinates are of the internal points of counties. A single point is identified for each county. According to the Census Bureau, this internal point represents the geographical center of the county in many cases. If the shape of a county causes this point to be located outside the boundary or in a water body, it is relocated to land area within the county.

23. This specification also fits the model expressed by Glaeser et al. [23], where the authors take a simple one-input production function (in which labor is the only input) and express the growth in technology as a combination of employment growth and wage growth.

24. Data on average earnings per job is also available from REIS. The earnings data include self-employers' income, largely on a place-of-residence basis, in addition to wage and salary disbursements (by place of work). Regressions using average earnings per job are attempted as an alternative of average wage and salary, and the earnings results are similar to the wage/salary results. In this paper, the change in log average wage and salary is chosen as a dependent variable instead of earnings due to the presence of negative values in average earnings, which would lead to missing values in the logarithm and in turn cause complication in spatial regressions.

25. See [23]. Please note that differences in nominal wages need not be completely eliminated in order for workers to be indifferent across locations. Costs of living, especially housing prices, are likely to rise in response to an increase in nominal wages.

26. On the other hand, the scopes, programs, sizes and student compositions of universities have changed over time. The variation in such changes would be highly endogenous if used to explain the variation in regional growth. For example, universities are likely to have grown more if they are in or near prosperous and/or growing counties. To avoid biased results arising from reverse causality, this study does not include such changes in the control set but instead focuses on the effects of the baseline characteristics of the institutions.

27. Also see Smith and Drabenstott [1].

28. Engineering programs include programs of engineering and engineering technology accredited by the Engineering Council for Professional Development. Business programs were accredited by the American Association of Collegiate Schools of Business. Medicine programs were accredited by the American Medical Association and Association of American Medical Colleges, Liaison Committee on Medical Education.

29. Specialized institutions may offer degrees ranging from the bachelors to the doctorate.
30. County population is not included in the control set due to near-perfect correlation with employment. We also experimented with controlling for population density in addition to the combination of land area and employment controls. This experiment produced essentially identical results to those reported in the next section.

31. Resource sectors include agriculture services, forestry, fishing and other, mining, and farm employment.

32. Comparable regressions without the state dummies were also estimated, the results of which are available upon request. Interestingly, most of the otherwise positive and significant coefficients of the IHE variables became insignificant and/or shifted toward the negative direction when the state dummies are excluded. This suggests that the growth-boosting effects of colleges are offset by, if omitted, some fixed characteristics of the states that had more colleges per county in 1970. In other words, the lower-growing states tend to have more colleges per county in 1970. A possible explanation is that some earlier developed and densely populated states have been losing population and employment to the less developed or sparsely populated states, and naturally, in 1970, colleges and universities (especially those old ones with high academic reputation) tend to concentrate in the states that were better developed and more populated at the time. This is related to the "slow down" phenomenon in economic growth. This interpretation is also supported by the changes in the coefficients of the baseline employment and county land area.

33. This is implied by the row-normalization in the standardized spatial weight matrix. I have also experimented with models using non-standardized spatial weight matrix, in which a spatial lag term indicates the aggregate number of colleges in all neighboring counties as opposed to the average. This specification gives results very similar to the reported ones using the standardized weight matrix, with the main difference being in the scales of the lag coefficient estimates. The lag coefficients associated with the non-standardized weight matrix are about one-sixth of the ones associated with the standardized matrix. Indeed, the average number of neighboring counties is six, and most counties have five to seven neighboring counties.

34. At least four special cases can be derived from the equations, including a so-called "mixed regressivespatial autoregressive model", featuring a spatially lagged dependent variable by assuming nonzero $\zeta$, $\rho=(0, \ldots, 0)^{\prime}$ and $\lambda=0$; and a "mixed regressivespatial cross-regressive model", featuring spatially lagged independent variables by assuming nonzero $\rho$ and $\zeta=$ $\lambda=0$; a "mixed regressive-spatial regressive model", a combination of the previous two models, which assumes nonzero $\zeta$ and $\rho$ and that $\lambda=0$; a "spatial autoregressive error model", which assumes nonzero $\lambda$ 
and that $\zeta=0, \rho=(0, \ldots, 0)^{\prime}$, capturing the spatial dependence coming from unobserved independent variables; see Florax [51].

\section{References}

[1] T. R. Smith and M. Drabenstott, "The role of universities in regional economic development," in The Economics of American Higher Education, D. R. Lewis, Ed., Kluwer Academic Publishers, Norwell, Mass, USA, 1992.

[2] S. Glendon, "Urban life cycles," in Economics, Harvard University, Boston, Mass, USA, 1999.

[3] A. Marshall, Principles of Economics, MacMillan, London, UK, 1890.

[4] P. M. Romer, "Increasing returns and long-run growth," Journal of Political Economy, vol. 94, pp. 1002-1037, 1986.

[5] P. M. Romer, "Endogenous technological change," Journal of Political Economy, vol. 98, no. 5, pp. S71-102, 1990.

[6] R. E. Lucas Jr., "On the mechanics of economic development," Journal of Monetary Economics, vol. 22, no. 1, pp. 3-42, 1988.

[7] E. L. Glaeser, "Learning in cities," Journal of Urban Economics, vol. 46, no. 2, pp. 254-277, 1999.

[8] D. Black and V. Henderson, "A theory of urban growth," Journal of Political Economy, vol. 107, no. 2, pp. 252-284, 1999.

[9] O. Olsson and C. Karlsson, "University policy for regional growth," Working Paper, 2000.

[10] A. B. Jaffe, "Technological opportunity and spillovers of R\&D: evidence from firms' patents, profits, and market value," American Economic Review, vol. 76, no. 5, pp. 984-1001, 1986.

[11] A. B. Jaffe, "Real effects of academic research," American Economic Review, vol. 79, no. 5, pp. 957-970.

[12] A. B. Jaffe, M. Trajtenberg, and R. Henderson, "Geographic localization of knowledge spillovers as evidenced by patent citations," Quarterly Journal of Economics, vol. 108, no. 3, pp. 577-598, 1993.

[13] L. Anselin, A. Varga, and Z. Acs, "Local geographic spillovers between university research and high technology innovations," Journal of Urban Economics, vol. 42, no. 3, pp. 422-448, 1997.

[14] A. Varga, University Research and Regional Innovation: A Spatial Econometric Analysis of Academic Technology Transfers, Kluwer Academic Publishers, Boston, Mass, USA, 1998.

[15] A. Varga, "Local academic knowledge transfers and the concentration of economic activity," Journal of Regional Science, vol. 40, no. 2, pp. 289-309, 2000.

[16] B. D. Jones and A. Vedlitz, "Higher education policies and economic growth in the American States," Economic Development Quarterly, vol. 2, pp. 78-87, 1988.

[17] Å. E. Andersson, C. Anderstig, and B. Hårsman, "Knowledge and communications infrastructure and regional economic change," Regional Science and Urban Economics, vol. 20, no. 3, pp. 359-376, 1990.

[18] D. Felsenstein, "The university in the metropolitan arena: impacts and public policy implications," Urban Studies, vol. 33, no. 9, pp. 1565-1580, 1996.

[19] E. L. Glaeser and A. Saiz, "The rise of the skilled city," Discussion Paper 2025, Harvard Institute of Economic Research, Cambridge, Mass, USA, 2003.

[20] R. K. Pace and R. Barry, "Sparse spatial autoregressions," Statistics and Probability Letters, vol. 33, no. 3, pp. 291-297, 1997.

[21] R. K. Pace and R. Barry, "Quick computation of regressions with a spatially autoregressive dependent variable," Geographical Analysis, vol. 29, no. 3, pp. 232-247, 1997.
[22] R. K. Pace and R. Barry, Spatial Statistics Toolbox 1.0, Real Estate Research Institute, Louisiana State University, Baton Rouge, La, USA, 1997.

[23] E. L. Glaeser, H. D. Kallal, and A. Jose, "Scheinkman and Andrei Shleifer. Growth in cities," Journal of Political Economy, vol. 100, no. 6, pp. 1126-1152, 1992.

[24] A. Glasmeier, The High-Tech Potential: Economic Development in Rural America, Center for Urban Policy Research, New Brunswick, NJ, USA, 1991.

[25] L. G. Zucker, M. R. Darby, and M. B. Brewer, "Intellectual human capital and the birth of U.S. biotechnology enterprises," American Economic Review, vol. 88, no. 1, pp. 290-306, 1998.

[26] D. Harhoff, "Firm formation and regional spillovers," The Economics of Innovation and New Technology, vol. 8, pp. 27$55,1999$.

[27] B. A. Kirchhoff, C. Armington, I. Hasan, and S. Newbert, The Influence of R\&D Expenditures on New Firm Formation and Economic Growth, National Commission on Entrepreneurship, Washington, DC, USA, 2002.

[28] E. Moretti, "Human capital externalities in cities," NBER Working Paper 9641, 2003.

[29] L. L. Leslie and S. A. Slaughter, "Higher education and regional development," in The Economics of American Higher Education, D. R. Lewis, Ed., Kluwer Academic Publishers, Norwell, Mass, USA, 1992.

[30] D. Card and Alan B. Krueger, "Does school quality matter? Returns to education and the characteristics of public schools in the United States," in Recent Developments in The Economics of Education, G. Johnes, Ed., Elgar, Aldershot, UK, 1994.

[31] E. L. Glaeser, "Why does schooling generate economic growth?” Economics Letters, vol. 44, no. 3, pp. 333-337, 1994.

[32] L. W. Kenny, "Returns to college education: an investigation of self selection bias based on the project talent data," in Econometric Method and Applications, G. S. Maddala, Ed., Elgar, Aldershot, UK, 1994.

[33] W. W. McMahon, "Relative returns to human and physical capital in the U.S. and efficient investment strategies," in Recent Developments in The Economics of Education, G. Johnes, Ed., Elgar, Aldershot, UK, 1994.

[34] J. Mincer, Collected Essays of Jacob Mincer, Volume 1: Studies in Human Capital, Elgar, Aldershot, UK, 1993.

[35] E. F. Denison, "The source of economic growth in the United States and the alternatives before us," Supplementary Paper 13, Committee for the Economic Development, New York, NY, USA, 1962.

[36] E. F. Denison, "Measuring the contribution of education (and the residual) to economic growth," in The Residual Factor and Economic Growth, OECD, Ed., Organization for Economic Cooperation and Development, Paris, France, 1964.

[37] E. F. Denison, "Accounting for slower economic growth: an update," in International Comparisons of Productivity and Causes of Slowdown, J. W. Kendrick, Ed., Ballinger, Cambridge, UK, 1984.

[38] L. L. Leslie and P. T. Brinkman, The Economic Value of Higher Education, Macmillan, New York, NY, USA, 1988.

[39] J. Caffrey and H. Isaacs, Estimating the Impact of a College or University on the Local Economy, American Council on Education, Washington, DC, USA, 1971.

[40] R. Premus, Location of High Technology Firms and Regional Economic Development, US Government Printing Office, Washington, DC, USA, 1982. 
[41] D. B. Audretsch and M. P. Feldman, "R\&D spillovers and the geography of innovation and production," American Economic Review, vol. 86, no. 3, pp. 630-640, 1996.

[42] E. J. Davelaar and P. Nijkamp, "Spatial dispersion of technological innovation: a case study for the Netherlands by means of partial least squares," Journal of Regional Science, vol. 29, no. 3, pp. 325-346, 1989.

[43] V. Henderson, "Externalities and industrial development," Journal of Urban Economics, vol. 42, no. 3, pp. 449-470, 1997.

[44] V. Henderson, A. Kuncoro, and M. Turner, "Industrial development in cities," Journal of Political Economy, vol. 103, no. 5, pp. 1067-1090, 1995.

[45] J. E. Rauch, "Productivity gains from geographic concentration of human capital: evidence from the cities," Journal of Urban Economics, vol. 34, no. 3, pp. 380-400, 1993.

[46] G. Peri, "Human capital externalities in US cities," Mimeo, University of California, Berkeley, Calif, USA, 1998.

[47] E. Moretti, "Human capital spillovers in manufacturing: evidence from plant-level production functions," NBER Working Paper 9316, 2002.

[48] J. M. Shapiro, "Smart cities: explaining the relationship between city growth and human capital," Mimeo, Harvard University, 2003.

[49] P. Cheshire and S. Magrini, "Urban growth drivers in a Europe of sticky people and implicit boundaries," Journal of Economic Geography, vol. 9, no. 1, pp. 85-115, 2009.

[50] M. H. Parsons, The Interaction of Economic Development and Education: Making High Technology Work, US Department of Education, Office of Educational Research and Improvement, Washington, DC, USA, 1988.

[51] R. Florax, The University: A Regional Booster? Economic Impacts of Academic Knowledge Infrastructure, Avebury, Brookfield, Wis, USA, 1992. 


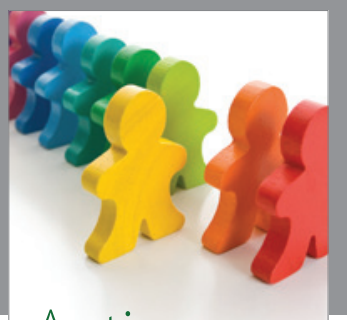

Autism

Research and Treatment
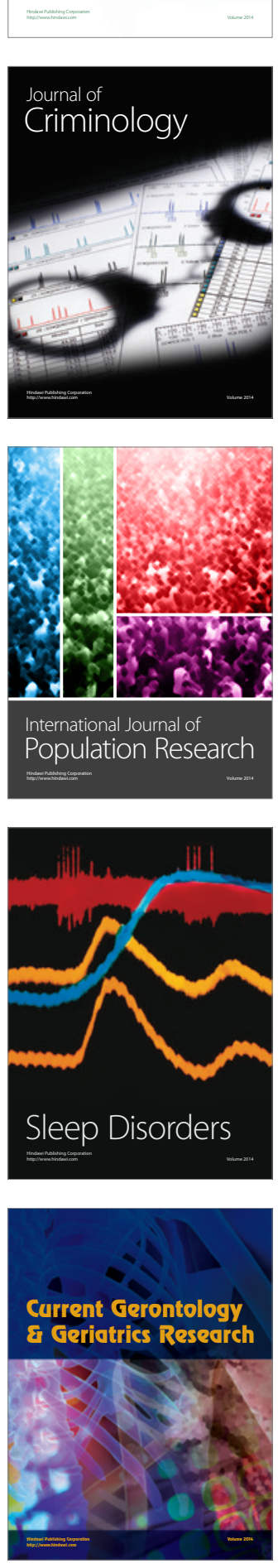
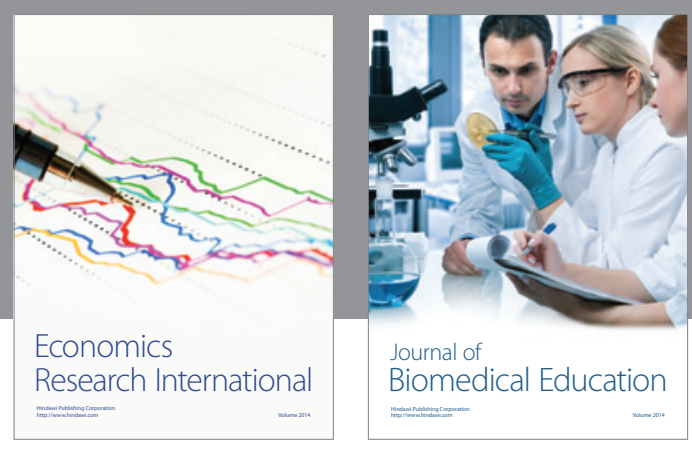

Journal of

Biomedical Education

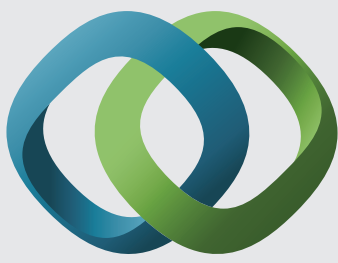

\section{Hindawi}

Submit your manuscripts at

http://www.hindawi.com
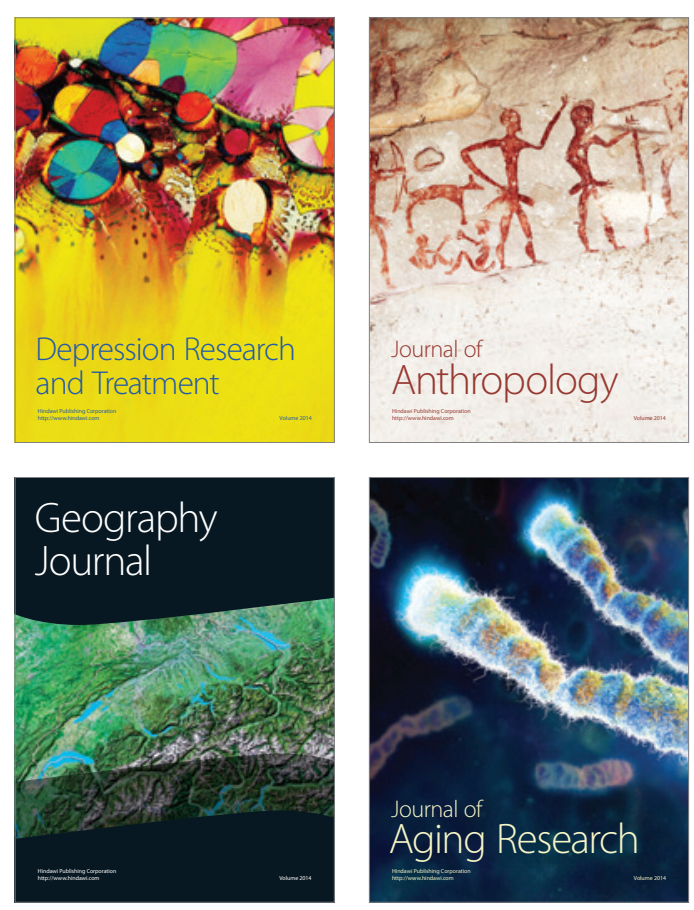

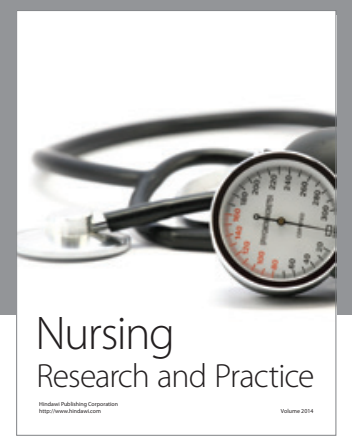

Nursing

Research and Practice

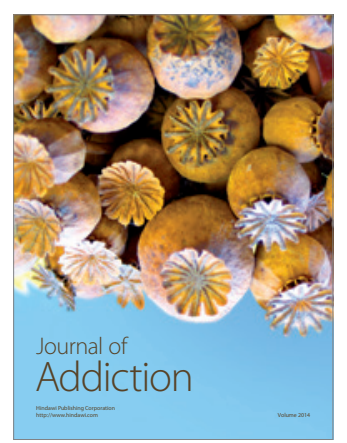

Child Development

Research

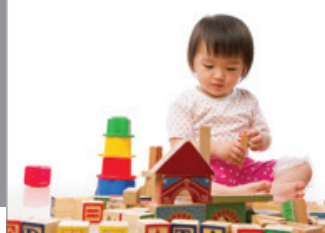

迥
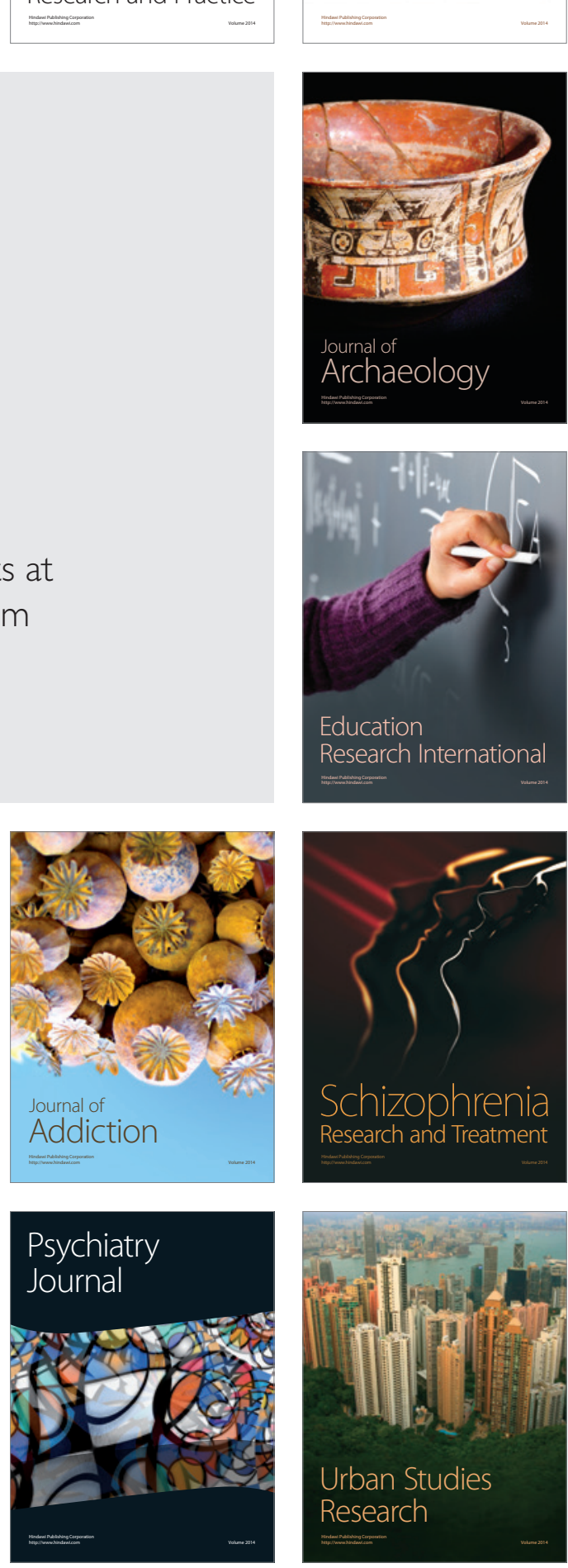